\section{Early Neonatal Sepsis Screening: Procalcitonin and C-Reactive Protein Diagnostic Value}

\author{
Joana Borges ${ }^{1 *}$, Ana Ventura', Paula Costa ${ }^{1,2}$, Margarida \\ Abrantes $^{1,2}$ and André Graça ${ }^{1,2}$
}

${ }^{1}$ Department of Paediatrics, Hospital de Santa Maria, Centro Hospitalar Universitário de Lisboa Norte, Lisbon, Portugal

${ }^{2}$ Faculty of Medicine, University of Lisbon, Lisbon, Portugal

\section{Abstract \\ Objective}

To evaluate the utility of procalcitonin and C-reactive protein for screening asymptomatic neonates with risk factors for early-onset sepsis.

\section{Study Design}

A consecutive cohort of term/late preterm newborns with at least one infectious risk factor was recruited. The primary outcome was to compare the accuracy of procalcitonin (cut-off $5 \mathrm{ng} / \mathrm{ml}$ ) for deciding antibiotic therapy and to compare its predictive value that of C-reactive protein (cut-off $2 \mathrm{mg} / \mathrm{dl}$ ). Authors were blinded to procalcitonin results and clinical decisions were made using $\mathrm{C}$-reactive protein only, per protocol.

\section{Results}

Ninety-three neonates were enrolled. Seven patients had a positive septic screen and started antibiotics. All blood cultures were negative. If procalcitonin was used to estimate a positive C-reactive protein value, it would show $57 \%$ of sensitivity and $82 \%$ of specificity ( $21 \%$ positive predictive value; $96 \%$ negative predictive value).

\section{Conclusion}

Our results discourage the use of procalcitonin for the diagnosis of early-onset sepsis in newborns with risk factors when using conventional cut-off values.

*Corresponding author: Joana Borges, Department of Paediatrics, Hospital de Santa Maria, Centro Hospitalar Universitário de Lisboa Norte, Lisbon, Portugal, Tel: +351 217805000; E-mail:borges.joana@gmail.com

Citation: Borges J, Ventura A, Costa P, Abrantes M, Graça A (2020) Early Neonatal Sepsis Screening: Procalcitonin and C-Reactive Protein Diagnostic Value. J Neonatol Clin Pediatr 7: 054.

Received: June 17, 2020; Accepted: June 25, 2020; Published: July 02, 2020

Copyright: (c) 2020 Borges J, et al. This is an open-access article distributed under the terms of the Creative Commons Attribution License, which permits unrestricted use, distribution, and reproduction in any medium, provided the original author and source are credited.
Keywords: Biomarkers; Neonatal sepsis; Neonatal screening; Newborn

\section{Introduction}

Diagnosis of Early-Onset Neonatal Sepsis (EOS) remains challenging and sepsis substantially contributes to neonatal morbidity and mortality $[1,2]$. EOSis usually associated with mother to foetustransmission of microbiological agents during the perinatal period, shortly before or during birth, and occurs, by definition, within the first 72 hours of life $[1,3]$.

The incidence of EOS in term and late preterm infants is low, generally $1-2 / 1000$ live births, but the potential for serious adverse outcomes should lead to alow threshold for evaluation and treatment of possible sepsis in neonates [4,5]. EOS mortality is about $10 \%$, with most deaths occurring within 48 hours from the onset of the infection[6]. Neonates with EOS can present initially with nonspecific and subtle clinical symptoms. Low sensitivity and specificity of current laboratory findings further complicate EOS diagnosis $[1,5]$. In the absence of clinical signs, most neonatal units do not treat based only on risk factors for EOS, requiring a positive biomarker to start antibiotics. Therefore, screening for EOS should be performed in infants with identifiable risk factors and/or signs and symptoms suggestive of sepsis, but the ideal combination of EOS biomarkers is still to be found.

A wide variety of acute-phase reactants have been evaluated in neonates as potential biomarkers for ruling out neonatal sepsis and to determine antibiotics suspension [4,7]. Although C-Reactive Protein (CRP) and Procalcitonin (PCT) concentrations are the most frequently used and both were investigated in sufficiently large studies, their diagnostic advantage remains controversial $[4,7,8]$.

CRP is considered to be a good biomarker for screening of neonatal sepsis since its concentration increases within 6 to 8 hours of an infectious episode in neonates and peaks at 24 hours $[9,10]$. The sensitivity of a CRP determination is low at birth but improves dramatically if the first determination is made 6 to 12 hours after birth [11]. Nevertheless, CRP increases are also detected in autoimmunity, post-surgery, perinatal asphyxia or other inflammatory processes and this marker also increases physiologically in newborns within the first days after birth $[9,12,13]$.

PCT is a biomarker with a potential earlier rise in response to infection, often used to differentiate sepsis from systemic inflammation, that can be useful to reduce antibiotic exposure in paediatric patients [14]. In response to infection, PCT concentrations increase within 2 hours and peak values are reached after 12 hours, even though a physiologic increase in PCT concentration has been shown to occur within the first24 hours after birth $[12,15]$.

Normal values for PCT and CRP concentrations according to hours of life and gestational age, as well as the influence of various prenatal and perinatal variables, were already published [12]. Some perinatal 
factors associated with changes in acute phase reactants were also described (prolonged rupture of membranes, antenatal steroid administration and intrapartum antimicrobial prophylaxis increase CRP, while only prolonged rupture of membranes increases PCT) $[12,16]$.

CRP is most commonly used in screening for neonatal sepsis, but some studies had shown that PCT can have better sensitivity and specificity $[4,17]$.

The objectives of this study were to evaluate the diagnostic accuracy of PCT in asymptomatic neonates with risk factors for EOS, when compared to CRP.

\section{Methods}

We designed a prospective single-center study conducted at a university hospital (HSM-CHULN) between May and October 2016, aimed to compare the diagnostic usefulness of PCT to CRP in EOS screening. A consecutive cohort of newborns was recruited according to protocol inclusion criteria: Term or late preterm newborns with at least one risk factor for EOS. The study protocol was based on local guidelines for EOS screening.

Approval was obtained from the local ethics committee. Written Informed consent was obtained from legal representatives before patient enrollment. The presence of signs or symptoms compatible with EOS, age above 30 hours of life at the time of recruitmentor parental refusal of informed consent were exclusion criteria.

Peripheral blood samples for routine laboratory investigations were collected from a peripheral vein, between 18 and 30 hours of life. CRP measurements were obtained by immunoturbidimetric technique (CRPL3,Cobas ${ }^{\circledR}$ reagent) and PCT by an electrochemiluminescence immunoassay -ECLIA (Elecsys BRAHMS PCT Cobas ${ }^{\circledR}$ reagent) using, for both assays, the Cobas 6000 analyzer $\left(\right.$ Roche $\left.^{\circledR}\right)$.

The primary outcome of the study was to assess the sensitivity and specificity of PCT as a biomarker to support the decision to initiate antibiotic therapy in infants with risk factors for EOS and to compare its predictive value that of CRP. The cut-off value used was $5 \mathrm{ng} / \mathrm{mL}$ for PCT, corresponding to the median value for PCT in our sample plus $1 \mathrm{SD}$, a value consistent with the physiological elevation that occurs in the first 72 hours of life, and $2 \mathrm{mg} / \mathrm{dL}$ for CRP, which corresponds to local protocol's cut-off to start antibiotics in the absence of clinical signs of infection [16,18-20,21]. Secondary outcomes were to evaluate the usefulness of the combined use of CRP and PCT in the decision to initiate antibiotic therapy, to increase the sensitivity and specificity of the diagnosis of EOS in this risk group.

The algorithm used for inclusion, clinical and laboratory evaluations and decision on therapeutic initiation is summarized in figure 1.

Researchers were blind to PCT values during the study to avoid changes in practice related to these results. Nevertheless, PCT values could be unblinded if requested by the clinician in particular circumstances, which was not necessary.

Statistical analysis was performed using $\operatorname{SPSS}^{\circledR} \mathrm{v} 23.0$. Categorical variables were analyzed using Fisher's exact test. The diagnostic usefulness of PCT compared to CPR was assessed by calculating its sensitivity, specificity, Positive Predictive Value (PPV) and Negative Predictive Value (NPV).

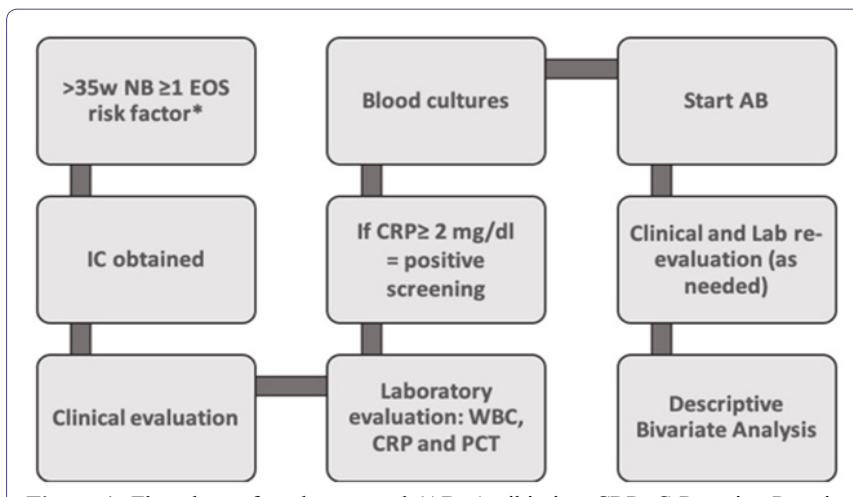

Figure 1: Flowchart of study protocol (AB: Antibiotics; CRP: C-Reactive Protein; EOS: Early Onset Sepsis; IC: Informed Consent; NB: Newborn; PCT: Procalcitonin; WBC: White Blood cell Count).

*EOS risk factors: Prolonged membrane rupture ( $\geq 18$ hours); Intrapartum fever ( $\geq$ $38^{\circ} \mathrm{C}$ ); Maternal positive septic screening (CRP $>2 \mathrm{mg} / \mathrm{dL}$ or leukocytosis $>20000$ cells/ $\mu \mathrm{L}$ with neutrophilia); Aminionitis; Positive Group B Streptococcus (GBS) vaginal/rectal smear without adequate prophylaxis ( $\geq 2$ Ampicillin administrations) or without elective C-section; GBS bacteriuria without adequate prophylaxis; Peripartum urinary tract infection without adequate treatment; Previous newborn with GBS infection, without adequate prophylaxis.

\section{Results}

During the study period, 113 patients were screenedand 93 neonates $(82 \%)$ wereenrolled. Meanbirth weight was $3266 \mathrm{~g}( \pm 479 \mathrm{~g})$ and gestational agewas 39,0 weeks ( \pm 1 week).

Most frequently found EOS risk factors were prolonged rupture of membranes (66\%), positive Group B Streptococcus (GBS) vaginal or rectal smear culture without adequate prophylaxis $(12 \%)$, positive maternal septic screen $(11 \%)$, maternal fever $(10 \%)$ and preterm membrane rupture $(7,5 \%)$ (Figure 2 ). None of the newborns presented with signs or symptoms of clinical sepsis during the study.

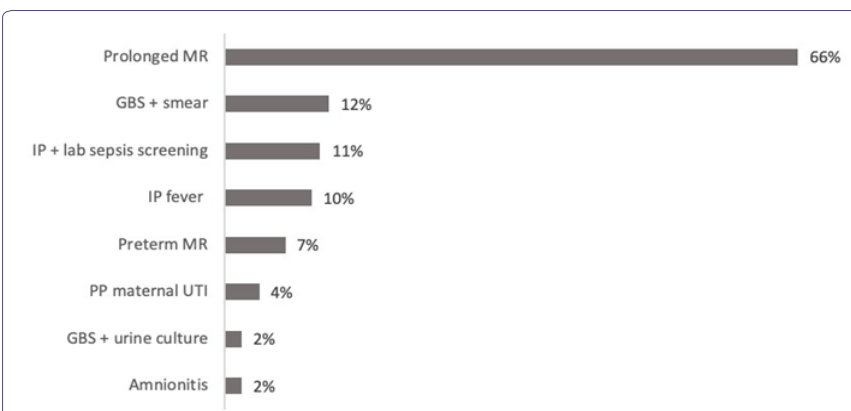

Figure 2: Incidence of early neonatal sepsis risk factors on study population. MR: Membrane rupture; GBS: Group B Streptococcus; IP: Intrapartum; lab: Laboratory; PP: Peripartum; UTI: Urinary tract infection; +: Positive.

Blood samples were obtained at a median age of 24 hours of life. Mean values observed for CRP were $0,64 \mathrm{mg} / \mathrm{dL} \pm 0,7(95 \%$ CI 0,50 $0,79)$ and $2,85 \mathrm{ng} / \mathrm{mL} \pm 3,1(95 \%$ CI $2,22-3,49)$ for PCT. Among the screened newborns, $94 \%$ had CRP values below the $2 \mathrm{mg} / \mathrm{dL}$ cut-off, whereas $80 \%$ had PCT values belowthe $5 \mathrm{ng} / \mathrm{mL}$ cut-off (Figure 3 ).

Seven patients $(7.5 \%)$ had a positive septic screen based on CRP values above $2 \mathrm{mg} / \mathrm{dL}$. Those patients were started on antibiotics based in the local protocol, independently of other laboratory tests findings. Blood cultures were negative in all 7 cases and all studied infants 
were asymptomatic throughout their hospital stay.If a PCT value above $5 \mathrm{ng} / \mathrm{mL}$ had been used alone as a sepsis risk discriminator instead of CRP, 19 patients (20\%) would have been considered with positive screening. Out of these 19 patients, 4 had also a positive CRP and therefore were initiated on antibiotics. As so, the use of PCT alone would have configured a $55 \%$ increase in antibiotic exposure. None of those untreated patients according to PCT screening developed symptoms nor was readmitted during the first month of life.

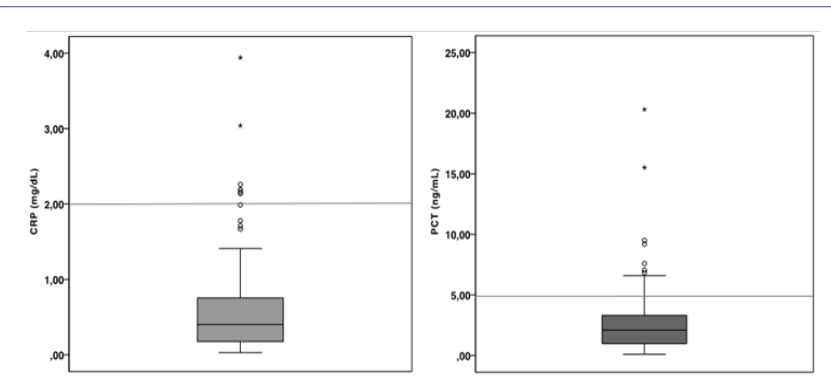

Figure 3: Laboratorial screening values obtained for CRP (left) and PCT (right). Horizontal lines indicate study cut-offs of $2 \mathrm{mg} / \mathrm{dL}$ for CRP and $5 \mathrm{ng} / \mathrm{mL}$ for PCT. Legend: CRP: C-reactive protein; PCT: Procalcitonin.

If PCT was used to estimate a CRP value $>2 \mathrm{mg} / \mathrm{dL}$, it would show low sensitivity $(57 \%)$ andmoderate specificity $(82 \%)$, which translates to a very low PPV (21\%) and quite high NPV (96\%). Thus, PCT and CRP exhibited a different profile when used to screen EOS in those newborns with risk factors, with a statistically significant difference on Fisher'sexact test $(\mathrm{p}<0.05)$.

\section{Discussion}

Multiple biomarkers have been investigated for early diagnosis of neonatal sepsis, including CRP, PCT, serum amyloid A or hepcidin [5]. CRP is the most commonly use biomarker for bacterial sepsis in neonates and children, but PCT has demonstrated diagnostic and therapeutic utility in a variety of clinical situations. It is a well-recognized and reliable serum marker for the presence or absence of invasive bacterial infection and response to antibiotic therapy in the paediatric population $[13,22]$. Recent studies also suggest that the use of PCT combined with other inflammatory markers such as IL-6 or IL-8 may represent a reasonable diagnostic approach to EOS [23]. However, the new borns have particularities that are reflected in a wide heterogeneity of reference ranges reported in the literature. There is no evidence to support the isolated use of PCT as a biomarker on those newborns at risk for sepsis.

The rapid increase of PCT levels would configure this marker as the preferred in EOS diagnosis. Since both CRP and PCT concentrations increase physiologically during the first days of life of a healthy new born and are also dependent on factors such as birth weight or gestational age, their use in EOS diagnostic is less accurate than desired, particularly if used immediately after birth [12]. There are no universally accepted reference values in this population for PCT, which limits its use in clinical practice. Recently, cut-off values for both CRP and PCT were investigated in a large study with healthy term and preterm newborns [12]. The predicted PCT normal ranges for term neonates were $0.01-0.55 \mathrm{ng} / \mathrm{mL}$ at birth, rising to peak levels of $0.4-18.7 \mathrm{ng} / \mathrm{mL}$ at 24 hours after birth, followed by a slow reduction to $0.04-1.8 \mathrm{ng} / \mathrm{mL}$ at about 80 hours of life [12]. Other authors report median values of $1.2 \mathrm{ng} / \mathrm{mL}$ and $2.2 \mathrm{ng} / \mathrm{mL}$ for late preterm and term infants, respectively [13].
The use of a PCT cut-off of $5 \mathrm{ng} / \mathrm{mL}$ identified more potentially positive screening cases than CRP. Therefore, if PCT was used alone as sepsis risk discriminator, 19 patients would have been exposed to antibiotics, instead of the 7 patients that were treated based on CRP screening. Four patients presented both simultaneously PCT and CRP above cut-off values. Since our protocol preconizes that only newborns that cumulatively present EOS risk factors and positive CRP (above $2 \mathrm{mg} / \mathrm{dL}$ ) must initiate treatment, 15 patients with a "positive" PCT remained untreated. None of those patients developed sepsis and none was readmitted to the hospital during the first month of life.

According to our results, a $13.6 \%$ reduction in exposure to antibiotics would have been observed if the screening protocol based the initial antibiotic decision on a concomitant positive CPR and PCT. Although all patients have negative blood cultures, we cannot be sure that this minimal approach is safe.

A previously meta-analysis demonstrated that PCT has a higher likelihood ratio than CRP to predict neonatal sepsis, but it is far more accurate in Late-Onset neonatal sepsis (LOS) than in EOS [17]. Other recent publications reported higher sensitivity and similar specificity for PCT for EOS when compared to CRP [3,4]. In our study, PCT and CRP also exhibited a significantly different profile when used to screen EOS in those newborns with risk factors $(\mathrm{p}<0.05)$.

Our conclusions are limited by the absence of clinical sepsis or positive blood cultures. A much larger multicenter study would be necessary to confirm the diagnostic value of PCT and CRP in EOS, as well as to evaluate the utility (safety and costs) of their combined use. On the other hand, this study led to question the adequacy of our protocol. Based on current scientific evidencea new center's protocol was adopted with a categorical assessment of risk factors and consequently fewer newborns with an indication for screening. To reduce prolonged and unnecessary exposure to antibiotic therapy this new protocol advised its suspension after a negative preliminary result of blood culture (after 48-72h) in the absence of clinical signs of sepsis. The development of locally adapted guidelines for the assessment of EOS risks is recommended and it is essential to maintain surveillance of its implementation [24].

\section{Conclusion}

The use of PCT as a determining factor for starting antibiotics would have resulted in a significant increase in the number of newborns exposed to unnecessary treatment. Given the absence of sepsis confirmed by culture or clinical signs, both during the hospitalization and after discharge, our results discourage the use of PCT alone for the screening of EOS in newborns with risk factors, when using the PCT cut-off of $5 \mathrm{ng} / \mathrm{mL}$.

\section{Conflict of Interests}

The authors have nothing to declare.

\section{Financing Sources or Awards}

None.

\section{Acknowledgment}

The authors would like to thank Dr. Teresa Amaral, from HSMCHULN Clinical Pathology Service, for the support in the implementation and conduct of laboratory tests. 
Citation: Borges J, Ventura A, Costa P, Abrantes M, Graça A (2020) Early Neonatal Sepsis Screening: Procalcitonin and C-Reactive Protein Diagnostic Value. J Neonatol Clin Pediatr 7: 054.

\section{References}

1. Bhandari V (2014) Effective biomarkers for diagnosis of neonatal sepsis. J Pediatric Infect Dis Soc 3: 234-245.

2. Dessì A, Corsello G, Stronati M, Gazzolo D, CaboniP, et al. (2014) New diagnostic possibilities in systemic neonatal infections: Metabolomics. Early Hum Dev 90: 90-92.

3. Ahmed AM, Mohammed AT, Bastawy S (2019) Original research 14: 2632.

4. Eschborn S, Weitkamp JH (2019) Procalcitonin versus C-reactive protein: Review of kinetics and performance for diagnosis of neonatal sepsis. J Perinatol 39: 893-903.

5. Hedegaard SS, Wisborg K, Hvas AM (2015) Diagnostic utility of biomarkers for neonatal sepsis - a systematic review. Infect Dis (Auck1) 47: 117124.

6. Shane AL, Stoll BJ (2013) Recent developments and current issues in the epidemiology, diagnosis, and management of bacterial and fungal neonatal sepsis. Am J Perinatol 30: 131-141.

7. Çelik HT, Portakal O, Yiłit Ş, Hasçelik G, Korkmaz A, et al. (2016) Efficacy of new leukocyte parameters versus serum C-reactive protein, procalcitonin, and interleukin- 6 in the diagnosis of neonatal sepsis. Pediatr Int 58: 119-125.

8. Benitz WE (2010) Adjunct laboratory tests in the diagnosis of early-onset neonatal sepsis. Clin Perinatol37: 421-438.

9. Adib M, Bakhshiani Z, Navaei F, Fosoul FS, Fouladi S, et al. (2012) Procalcitonin: A reliable marker for the diagnosis of Neonatal sepsis. Iran J Basic Med Sci 15: 777-782.

10. Philip A (1985) Response of C-reactive protein in neonatal Group B streptococcal infection. Pediatr Infect Dis4:145-148.

11. Benitz WE, Han MY, Madan A, Ramachandra P (1998) Serial Serum C-Reactive Protein Levels in the Diagnosis of Neonatal Infection. Pediatrics 102 .

12. Chiesa C, Natale F, Pascone R, Osborn JF, Pacifico L, et al. (2011) C reactive protein and procalcitonin: Reference intervals for preterm and term newborns during the early neonatal period. Clin Chim Acta 412: 1053 1059 .

13. Fukuzumi N, Osawa K, Sato I, Iwatani S, Ishino R, et al. (2016) Age-specific percentile-based reference curve of serum procalcitonin concentration in Japanese preterm infants. Nat Publ Gr 6: 23871.
14. Agarwal S, Akbas N, Soundar EP, Gonzalez G, Devaraj S (2015) Validation of the procalcitonin (PCT) assay: Experience in a pediatric hospital. Clin Biochem 48: 886-890.

15. Das T, Johnson A (1998) Lack of specificity of procalcitonin for sepsis diagnosis in premature infants. Lancet351: 1211-1212.

16. Chiesa C, Pellegrini G, Panero A, Osborn JF, Signore F, et al. (2003) C-reactive protein, interleukin- 6 , andprocalcitonin in the immediate postnatal period: Influence of illness severity, risk status, antenatal and perinatal complications, and infection. Clin Chem 49: 60-68.

17. Vouloumanou EK, Plessa E, Karageorgopoulos DE, Mantadakis E, Falagas ME (2011) Serum procalcitonin as a diagnostic marker for neonatal sepsis: A systematic review and meta-analysis. Intensive Care Med 37: 747-762.

18. Chiesa C, Pacifico L, Osborn JF, Bonci E, Hofer N, et al. (2015) Early-onset neonatal sepsis. Medicine (Baltimore) 94: 1230.

19. Hofer N, Müller W (2012) An update on the use of C-reactive protein in early-onset neonatal sepsis: Current insights and new tasks. Neonatology102: 25-36.

20. Stocker M, Hop WC, van Rossum AM (2010) Neonatal procalcitonin intervention study (neopins): effect of procalcitonin-guided decision making on duration of antibiotic therapy in suspected neonatal early-onset sepsis: A multi-centre randomized superiority and non-inferiority intervention Study. BMC Pediatr 10: 89

21. ChiesaC, Panero A, Osborn JF, Simonetti AF, PAcifico L (2004) Opinion Diagnosis of Neonatal Sepsis : A Clinical and Laboratory Challenge. Clin Chem 50:279-287.

22. Pierce R, Bigham MT, Giuliano JS (2014) Use of procalcitonin for the prediction and treatment of acute bacterial infection in children26:292-298.

23. Pontrelli G, Crescenzo F De, Buzzetti R, Jenkner A, Balduzzi S, et al. (2017) Accuracy of serum procalcitonin for the diagnosis of sepsis in neonates and children with systemic inflammatory syndrome: A meta-analysis. BMC Infect Dis 17: 302.

24. Puopolo KM, Benitz WE, Zaoutis T (2018) Management of neonates born at $\leq 34$ 6/7 weeks' gestation with suspected or proven early-onset bacterial sepsis. Pediatrics 142: 20182896. 


\section{If}

Advances In Industrial Biotechnology | ISSN: 2639-5665

Advances In Microbiology Research | ISSN: 2689-694X

Archives Of Surgery And Surgical Education | ISSN: 2689-3126

Archives Of Urology

Archives Of Zoological Studies | ISSN: 2640-7779

Current Trends Medical And Biological Engineering

International Journal Of Case Reports And Therapeutic Studies | ISSN: 2689-310X

Journal Of Addiction \& Addictive Disorders | ISSN: 2578-7276

Journal Of Agronomy \& Agricultural Science | ISSN: 2689-8292

Journal Of AIDS Clinical Research \& STDs | ISSN: 2572-7370

Journal Of Alcoholism Drug Abuse \& Substance Dependence | ISSN: 2572-9594

Journal Of Allergy Disorders \& Therapy | ISSN: 2470-749X

Journal Of Alternative Complementary \& Integrative Medicine | ISSN: 2470-7562

Journal Of Alzheimers \& Neurodegenerative Diseases | ISSN: 2572-9608

Journal Of Anesthesia \& Clinical Care | ISSN: 2378-8879

Journal Of Angiology \& Vascular Surgery | ISSN: 2572-7397

Journal Of Animal Research \& Veterinary Science | ISSN: 2639-3751

Journal Of Aquaculture \& Fisheries | ISSN: 2576-5523

Journal Of Atmospheric \& Earth Sciences | ISSN: 2689-8780

Journal Of Biotech Research \& Biochemistry

Journal Of Brain \& Neuroscience Research

Journal Of Cancer Biology \& Treatment | ISSN: 2470-7546

Journal Of Cardiology Study \& Research | ISSN: 2640-768X

Journal Of Cell Biology \& Cell Metabolism | ISSN: 2381-1943

Journal Of Clinical Dermatology \& Therapy | ISSN: 2378-8771

Journal Of Clinical Immunology \& Immunotherapy | ISSN: 2378-8844

Journal Of Clinical Studies \& Medical Case Reports | ISSN: 2378-8801

Journal Of Community Medicine \& Public Health Care | ISSN: 2381-1978

Journal Of Cytology \& Tissue Biology | ISSN: 2378-9107

Journal Of Dairy Research \& Technology | ISSN: 2688-9315

Journal Of Dentistry Oral Health \& Cosmesis | ISSN: 2473-6783

Journal Of Diabetes \& Metabolic Disorders | ISSN: 2381-201X

Journal Of Emergency Medicine Trauma \& Surgical Care | ISSN: 2378-8798

Journal Of Environmental Science Current Research | ISSN: 2643-5020

Journal Of Food Science \& Nutrition | ISSN: 2470-1076

Journal Of Forensic Legal \& Investigative Sciences | ISSN: 2473-733X

Journal Of Gastroenterology \& Hepatology Research | ISSN: 2574-2566
Journal Of Genetics \& Genomic Sciences | ISSN: 2574-2485

Journal Of Gerontology \& Geriatric Medicine | ISSN: 2381-8662

Journal Of Hematology Blood Transfusion \& Disorders | ISSN: 2572-2999

Journal Of Hospice \& Palliative Medical Care

Journal Of Human Endocrinology | ISSN: 2572-9640

Journal Of Infectious \& Non Infectious Diseases | ISSN: 2381-8654

Journal Of Internal Medicine \& Primary Healthcare | ISSN: 2574-2493

Journal Of Light \& Laser Current Trends

Journal Of Medicine Study \& Research | ISSN: 2639-5657

Journal Of Modern Chemical Sciences

Journal Of Nanotechnology Nanomedicine \& Nanobiotechnology | ISSN: 2381-2044

Journal Of Neonatology \& Clinical Pediatrics | ISSN: 2378-878X

Journal Of Nephrology \& Renal Therapy | ISSN: 2473-7313

Journal Of Non Invasive Vascular Investigation | ISSN: 2572-7400

Journal Of Nuclear Medicine Radiology \& Radiation Therapy | ISSN: 2572-7419

Journal Of Obesity \& Weight Loss | ISSN: 2473-7372

Journal Of Ophthalmology \& Clinical Research | ISSN: 2378-8887

Journal Of Orthopedic Research \& Physiotherapy | ISSN: 2381-2052

Journal Of Otolaryngology Head \& Neck Surgery | ISSN: 2573-010X

Journal Of Pathology Clinical \& Medical Research

Journal Of Pharmacology Pharmaceutics \& Pharmacovigilance | ISSN: 2639-5649

Journal Of Physical Medicine Rehabilitation \& Disabilities | ISSN: 2381-8670

Journal Of Plant Science Current Research | ISSN: 2639-3743

Journal Of Practical \& Professional Nursing | ISSN: 2639-5681

Journal Of Protein Research \& Bioinformatics

Journal Of Psychiatry Depression \& Anxiety | ISSN: 2573-0150

Journal Of Pulmonary Medicine \& Respiratory Research | ISSN: 2573-0177

Journal Of Reproductive Medicine Gynaecology \& Obstetrics | ISSN: 2574-2574

Journal Of Stem Cells Research Development \& Therapy | ISSN: 2381-2060

Journal Of Surgery Current Trends \& Innovations | ISSN: 2578-7284

Journal Of Toxicology Current Research | ISSN: 2639-3735

Journal Of Translational Science And Research

Journal Of Vaccines Research \& Vaccination | ISSN: 2573-0193

Journal Of Virology \& Antivirals

Sports Medicine And Injury Care Journal | ISSN: 2689-8829

Trends In Anatomy \& Physiology | ISSN: 2640-7752

Submit Your Manuscript: https://www.heraldopenaccess.us/submit-manuscript 